NASA/TM-2000-210066

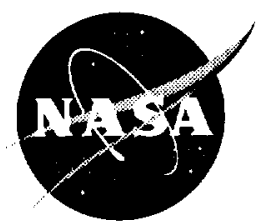

\title{
Effect of Air and Vacuum Storage on the Tensile Properties of X-ray Exposed Aluminized-FEP
}

Kim K. de Groh

Glenn Research Center, Cleveland, Ohio

Jonathan D. Gummow

Ohio Aerospace Institute, Brook Park, Ohio 
Since its founding, NASA has been dedicated to the advancement of aeronautics and space science. The NASA Scientific and Technical Information (STI) Program Office plays a key part in helping NASA maintain this important role.

The NASA STI Program Office is operated by Langley Research Center, the Lead Center for NASA's scientific and technical information. The NASA STI Program Office provides access to the NASA STI Database, the largest collection of aeronautical and space science STI in the world. The Program Office is also NASA's institutional mechanism for disseminating the results of its research and development activities. These results are published by NASA in the NASA STI Report Series, which includes the following report types:

- TECHNICAL PUBLICATION. Reports of completed research or a major significant phase of research that present the results of NASA programs and include extensive data or theoretical analysis. Includes compilations of significant scientific and technical data and information deemed to be of continuing reference value. NASA's counterpart of peerreviewed formal professional papers but has less stringent limitations on manuscript length and extent of graphic presentations.

- TECHNICAL MEMORANDUM. Scientific and technical findings that are preliminary or of specialized interest, e.g., quick release reports, working papers, and bibliographies that contain minimal annotation. Does not contain extensive analysis.

- CONTRACTOR REPORT. Scientific and technical findings by NASA-sponsored contractors and grantees.
- CONFERENCE PUBLICATION. Collected papers from scientific and technical conferences, symposia, seminars, or other meetings sponsored or cosponsored by NASA.

- SPECIAL PUBLICATION. Scientific, technical, or historical information from NASA programs, projects, and missions, often concerned with subjects having substantial public interest.

- TECHNICAL TRANSLATION. Englishlanguage translations of foreign scientific and technical material pertinent to NASA's mission.

Specialized services that complement the STI Program Office's diverse offerings include creating custom thesauri, building customiz data bases, organizing and publishing resea results ... even providing videos.

For more information about the NASA STI Program Office, see the following:

- Access the NASA STI Program Home Pa at http://www.sti.nasa.gov

- E-mail your question via the Internet to help@sti.nasa.gov

- Fax your question to the NASA Access Help Desk at (301) 621-0134

- Telephone the NASA Access Help Desk at (301) 621-0390

- Write to:

NASA Access Help Desk

NASA Center for AeroSpace Information 7121 Standard Drive

Hanover, MD 21076 
NASA/TM-2000-210066

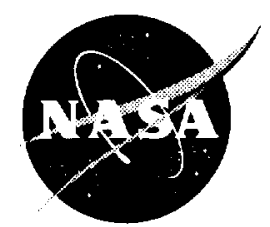

\section{Effect of Air and Vacuum Storage on the Tensile Properties of X-ray Exposed Aluminized-FEP}

Kim K. de Groh

Glenn Research Center, Cleveland, Ohio

Jonathan D. Gummow

Ohio Aerospace Institute, Brook Park, Ohio

Prepared for the

8th International Symposium on Materials in a Space Environment and the 5 th International Conference on Protection of Materials and Structures for the LEO Space Environment cosponsored by the CNES, ONERA, ESA, ITL, Inc., and the CSA Arachon, France, June 5-9, 2000

National Aeronautics and Space Administration

Glenn Research Center 


\section{Acknowledgments}

The authors would like to thank Dr. Donald Wheeler and Dr. Stephen Pepper of the NASA Glenn Research

Center for the use of their x-ray facility, and for quantitative characterization of the $x$-ray source and energy deposition within the FEP samples. The authors are also very appreciative to Douglas Wright of Cleveland State University for computing the percent elongation to failure for the test data, and Russell Messer, also of Cleveland State University for writing the program for elongation computation.

Trade names or manufacturers' names are used in this report for identification only. This usage does not constitute an official endorsement, either expressed or implied, by the National Aeronautics and Space Administration.

Available from

NASA Center for Aerospace Information 7121 Standard Drive

Hanover, MD 21076

Price Code: A03
National Technical Information Service 5285 Port Royal Road Springfield, VA 22100

Price Code: A03 


\title{
EFFECT OF AIR AND VACUUM STORAGE ON THE TENSILE PROPERTIES OF X-RAY EXPOSED ALUMINIZED-FEP
}

\author{
Kim K. De Groh \\ National Aeronautics and Space Administration \\ Glenn Research Center \\ 21000 Brookpark Rd., M.S. 309-2 \\ Cleveland, $\mathrm{OH} 44135$ \\ Telephone: (216) 433-2297, E-mail: Kim.deGroh@grc.nasa.gov \\ Jonathan D. Gummow \\ Ohio Aerospace Institute \\ 22800 Cedar Point Road \\ Brook Park, OH 44142
}

\begin{abstract}
Metallized Teflon $\left.{ }^{(}\right)$FEP (fluorinated ethylene propylene), a common spacecraft thermal control material, from the exterior layer of the Hubble Space Telescope (HST) has become embrittled and suffers from extensive cracking. Teflon samples retrieved during Hubble servicing missions and from the Long Duration Exposure Facility ( $L D E F$ ) indicate that there may be continued degradation in tensile properties over time. An investigation has been conducted to evaluate the effect of air and vacuum storage on the mechanical properties of $x$-ray exposed FEP. AluminizedFEP (Al-FEP) tensile samples were irradiated with $15.3 \mathrm{kV} \mathrm{Cu} x$-rays and stored in air or under vacuum for various time periods. Tensile data indicate that samples stored in air display larger decreases in tensile properties than for samples stored under vacuum. Air-stored samples developed a hazy appearance, which corresponded to a roughening of the aluminized surface. Optical property changes were also characterized. These findings indicate that air exposure plays a role in the degradation of irradiated FEP, therefore proper sample handling and storage is necessary with materials retrieved from space.
\end{abstract}

\section{1 - INTRODUCTION}

Metallized Teflon ${ }^{\circledR}$ FEP, a common thermal control material used on spacecraft, such as the Long Duration Exposure Facility and the Hubble Space Telescope, has been found to degrade in the low Earth orbit (LEO) space environment. Teflon ${ }^{(B)}$ FEP is used as the outer layer of thermal control insulation because of its excellent optical properties (low solar absorptance and high thermal emittance). A metallized layer is applied to the backside of the FEP to reflect incident solar energy. The solar absorptance $\left(\alpha_{s}\right)$ and thermal emittance $(\varepsilon)$ of $127 \mu \mathrm{m}(5 \mathrm{mil})$ Teflon with an aluminized backing is typically 0.13 and 0.81 , respectively. 'Solar radiation (ultraviolet radiation and x-rays from solar flares), electron and proton radiation (omni-directional particles trapped in the Van Allen belts), thermal exposure and thermal cycling, and atomic oxygen exposure are all possible LEO environmental factors which could contribute to the FEP degradation. 
The LDEF spacecraft was retrieved on January 11,1990 after 69 months in the space environment. ${ }^{2.3}$ The silvered-FEP (Ag-FEP) blankets from the trailing edge of LDEF, which received high solar fluences and very low atomic oxygen fluences, were found to be embrittled and developed surface cracking under tensile bending. ${ }^{4.5}$ The leading edge which received a high atomic oxygen fluence, and similar solar fluences, was found to be eroded but remained ductile. ${ }^{5.6}$

The HST was launched on April 25, 1990 into low Earth orbit and is the first mission of NASA's Great Observatories program. The HST was designed to be serviced on-orbit to upgrade scientific capabilities. The first servicing mission (SMI) occurred in December 1993, after 3.6 years in space. The second servicing mission (SM2) was in February 1997, after 6.8 years in space. The third servicing mission (SM-3A) was in December 1999, after almost 10 years in space. Servicing missions are also planned for mid 2001 and 2004.

Analyses of Al-FEP and Ag-FEP multilayer insulation (MLI) blankets retrieved during SM1 revealed that the $127 \mu \mathrm{m}$ thick FEP exterior layer was embrittled on high solar exposure surfaces. ${ }^{5.7}$ Surfaces which received the highest solar exposures had microscopic through-thickness cracks in the FEP at stress locations. ${ }^{5.7}$ During SM2, severe cracking of the MLI outer layer material (127 $\mu \mathrm{m}$ thick Al-FEP) was observed on the light shield, forward shell and equipment bays of the telescope. Astronaut observations combined with photographic documentation of HST taken during SM2, revealed extensive cracking of the MLI in many locations around the telescope, with solar facing surfaces being particularly heavily damaged. ${ }^{8}$ Embrittlement of FEP on HST is believed to be caused by radiation exposure (primarily electron and proton radiation with contributions from $\mathrm{x}$-rays from solar flares and UV radiation) combined with thermal cycling. ${ }^{9}$

As part of the continued investigation of the damage mechanism of FEP in the space environment, a very small number of samples, due to limited available material, were tensile tested long after initial post-retrieval tests. These data are shown in Table 1 along with the original post-retrieval data. The results indicate that there might be continued degradation in the tensile properties of the space-exposed materials over time stored on the ground. Because of the limited amount of space-exposed material available, ground-based tests were conducted to determine if irradiated FEP continues to degrade over time. One possible explanation to continued degradation is the interaction of molecular oxygen with long-lived radicals that are formed in-space due to molecular bond breaking caused by irradiation exposure. An investigation has therefore been conducted to evaluate the effect of air and vacuum storage on the mechanical properties of irradiated FEP. X-rays were used for the source of irradiation because $\mathrm{x}$-rays from solar flares are believed to contribute to the embrittlement of FEP on HST, ${ }^{9}$ and because previous ground tests have shown that solar flare $\mathrm{x}$-ray energies are energetic enough to cause bulk embrittlement in $127 \mu \mathrm{m}$ FEP. ${ }^{10}$ Also, the mechanism of embrittlement of FEP is believed to be the same for all forms of ionizing radiation, therefore $\mathrm{x}$-ray exposure is a very useful technique for understanding radiation damage effects in Teflon. 
Table 1. Tensile Data for HST and LDEF Samples Tested At Various Post-Retrieval Times.

\begin{tabular}{|c|c|c|c|c|c|}
\hline Source & Date & $\begin{array}{c}127 \mu \mathrm{m} \text { FEP } \\
\text { Solar Exposure, AO Fluence } \\
\left(\text { ESH, atoms } / \mathrm{cm}^{2}\right) \\
\end{array}$ & $\begin{array}{c}\text { Samples } \\
\text { Tested } \\
(\#) \\
\end{array}$ & $\begin{array}{c}\text { \% Elongation to } \\
\text { Failure } \\
\text { Relative to Pristine } \\
\end{array}$ & $\begin{array}{l}\text { UTS } \\
\text { (MPa) }\end{array}$ \\
\hline \multicolumn{6}{|c|}{ HST Samples (Retrieved December 1993) } \\
\hline Zuby et al. ${ }^{7}$ & 1994 & $\begin{array}{c}\text { Pristine } \\
\text { MLI SM1 }(11,339,<3.0 \text { E20 })\end{array}$ & $\begin{array}{l}1 \\
2\end{array}$ & $\begin{array}{c}100 \\
45\end{array}$ & $\begin{array}{l}27.2 \\
14.7\end{array}$ \\
\hline Banks et al..$^{10}$ & 1998 & $\begin{array}{c}\text { Pristine } \\
\text { MLI SM1 }(11,339,<3.0 \text { E20) } \\
\end{array}$ & $\begin{array}{l}9 \\
1 \\
\end{array}$ & $\begin{array}{l}100 \\
21 \\
\end{array}$ & $\begin{array}{l}19.2 \\
13.6 \\
\end{array}$ \\
\hline \multicolumn{6}{|c|}{ LDEF Samples (Retrieved January 1990) } \\
\hline Pippen $^{6}$ & $<1995$ & $\begin{array}{l}\text { LDEF Ground Control } \\
\text { LDEF D01 }(7437,2.9 \text { E17) } \\
\text { LDEF F04 }(10,458,2.3 \text { E5) }\end{array}$ & $\begin{array}{l}2 \\
2 \\
2\end{array}$ & $\begin{array}{l}100 \\
102 \\
71\end{array}$ & $\begin{array}{c}- \\
9.90 \\
13.0\end{array}$ \\
\hline Hall \& Banks ${ }^{11}$ & 1998 & $\begin{array}{l}\text { LDEF Ground Control } \\
\text { LDEF D01 }(7437,2.9 \text { E17) } \\
\text { LDEF F04 }(10,458,2.3 \text { E5) }\end{array}$ & $\begin{array}{l}1 \\
1 \\
1\end{array}$ & $\begin{array}{c}100 \\
36 \\
30\end{array}$ & $\begin{array}{l}24.0 \\
14.0 \\
12.8\end{array}$ \\
\hline
\end{tabular}

\section{2 - MATERIALS \& EXPERIMENTAL PROCEDURES}

2.1 Material (Pristine Al-FEP) Teflon ${ }^{\circledR}$ FEP is a perfluorinated copolymer of tetrafluoroethylene (TFE) and hexafluoropropylene (HFP). The Al-FEP material was 5 mil $(127 \mu \mathrm{m})$ thick FEP coated on the backside with $1000 \AA$ of vapor deposited $\mathrm{Al}$ (VDA) from Sheldahl, Inc.

2.2 X-Ray Exposure A modified X-ray photoelectron spectroscopy (XPS) facility was used to irradiate the FEP side of the Al-FEP tensile samples. A copper target was irradiated with a $15.3 \mathrm{kV}, 30 \mathrm{~mA}$ electron beam producing $\mathrm{Cu} x$-rays. The tensile samples were located $30.5 \mathrm{~mm}$ from the target, and the $\mathrm{Cu} x$-rays were filtered through a $2 \mu \mathrm{m} \mathrm{Al}$ window (part of the $\mathrm{x}$-ray tube). A $25 \mathrm{mil}(635 \mu \mathrm{m})$ thick beryllium filter was placed over the FEP samples to absorb the low energy $\mathrm{Cu} \mathrm{L}$ components $(930 \mathrm{eV})$, which would contribute significantly to damage of just the surface. ${ }^{12}$ The $\mathrm{x}$-ray flux was $13.28 \mathrm{~W} / \mathrm{m}^{2} .^{13}$ The choice of target material, electron beam energy, and filter was chosen to produce a high flux, uniform distribution of energy absorbed versus depth in the film. Figure 1 shows the energy deposition rate, or dose rate, versus depth below the surface for $127 \mu \mathrm{m}$ FEP film for the exposure conditions used $(\mathrm{Gy}=\mathrm{Gray}=100 \mathrm{Rads}=\mathrm{Joule} / \mathrm{kg}){ }^{12.14}$ The technique used to characterize the $\mathrm{x}$-ray source and energy deposition within the FEP film is described in detail by Pepper and Wheeler in reference 12. Pepper $e t$ al. provide quantitative characterization of the $\mathrm{Cu} \mathrm{x}$-ray source and the absorbed energy deposition rate within a Teflon film in reference 13. 


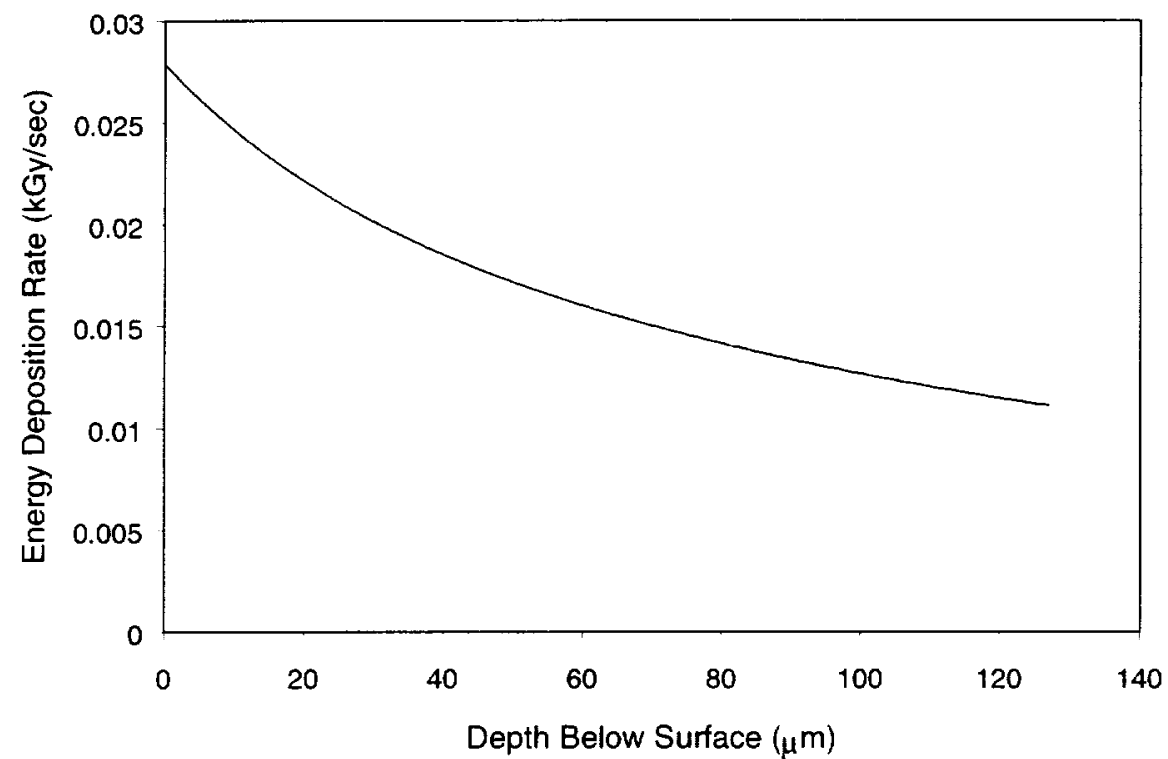

Fig. 1: Energy deposition rate in $127 \mu \mathrm{m}$ thick FEP as a function of depth below the surface.

2.3 Air and Vacuum Storage X-ray exposed tensile samples were stored in the following three different environments: fluoropolymer containers in ambient air, high vacuum, or low vacuum. High vacuum storage, $10^{-8}$ Torr, was in the actual facility used for $x$-ray exposure. The low vacuum $(60-100$ mTorr) was within a vacuum desiccator. Samples were quickly transferred from the research facility to the desiccator to make available the $\mathrm{x}$-ray facility for additional irradiation exposures.

2.4 Tensile Properties Samples for tensile testing were 'dog bone' shaped and die-cut using a tensile specimen die manufactured according to ASTM D638-95, type V. The tensile samples were $3.18 \mathrm{~mm}$ wide in the narrow section, with a $9.5 \mathrm{~mm}$ gauge length. All samples were cut from the same stock material, parallel to the roll direction. The samples were tested at a rate of $1.27 \mathrm{~cm} / \mathrm{min}$.

2.5 Optical Properties Solar reflectance (total $\left(\rho_{t}\right)$, diffuse $\left(\rho_{d}\right)$ and specular $\left(\rho_{s}\right)$ ), solar absorptance, and room temperature emittance $\left(\varepsilon_{\mathrm{RT}}\right)$ were obtained on a sample (identified as sample FEPOP3) prepared for optical property characterization. The sample's reflectance (total and diffuse) values were measured with a Perkin-Elmer $\lambda$-19 Spectrophotometer operated with a $150 \mathrm{~mm}$ integrating sphere within the range of 250 to $2500 \mathrm{~nm}$. Data from the $\lambda-19$ was convoluted into the air mass zero solar spectrum to obtain $\rho_{\mathrm{t}}$ and $\rho_{\mathrm{d}}{ }^{15}$ The value for $\rho_{\mathrm{s}}$ is the difference between $\rho_{\mathrm{t}}$ and $\rho_{\mathrm{d}}$. The value for $\alpha_{\mathrm{s}}$ is the difference between 1.0 and $\rho_{\mathrm{t}}$. Room temperature emittance was obtained using a Gier Dunkel DB100 infrared reflectometer, which provided an integrated reflectance value that was subtracted from 1 to get $\varepsilon_{\mathrm{RT}}$.

2.6 Surface Characterization Optical micrographs were taken of tensile and optical samples using an Olympus SZH Stereo-zoom microscope. The surface topography of both the FEP and Al sides of exposed and unexposed regions of air-stored $x$-ray exposed samples were examined using scanning electron microscopy and atomic force microscopy. Electron micrographs were taken using a JEOL 6100 scanning electron microscope (SEM) operated at an accelerating voltage of $15 \mathrm{kV}$. A sample 
(FEPCu42AB), originally irradiated and air-stored for tensile testing, was cut in half and coated with a thin conductive layer of $\mathrm{Pd}$ prior to examination. Atomic force microscope (AFM) images were obtained on an optical sample (FEPOP1) using a Park Scientific AutoProbe scanning probe microscope. Areas from 5 to $74 \mu \mathrm{m}$ square were imaged. The images were flattened using identical techniques to remove background curvature introduced as a scanning artifact. The average root mean square (RMS) roughness was computed for each scan size.

\section{3 - RESULTS \& DISCUSSION}

3.1 Preliminary X-Ray Tests A series of tests were conducted to find the optimal exposure conditions and maximum number of samples, for repeatable reduction in tensile properties. It was desired to have an initial reduction in the percent elongation to failure of $\approx 50 \%$ of the pristine material, prior to storage testing. The UTS and percent elongation to failure for 14 pristine samples was $18.6 \pm 1.3 \mathrm{MPa}$ and $214.5 \pm 20.8 \%$, respectively. It was determined that a 2-hour exposure would provide the desired reduction in tensile properties. The maximum number of samples that could be uniformly exposed at a time was two. The samples were centered in a holder that provided a $2.0 \mathrm{~cm}$ wide exposure area (the tensile sample gauge length is $\approx 1 \mathrm{~cm}$ ). Figure 2 shows two tensile samples loaded in the sample holder, along with the sample labeling. The total energy absorbed per unit area integrated through the full thickness (the areal dose, D) of the $127 \mu \mathrm{m}$ foil for the 2 hour exposure was $33.8 \mathrm{~kJ} / \mathrm{m}^{2}{ }^{1+}$

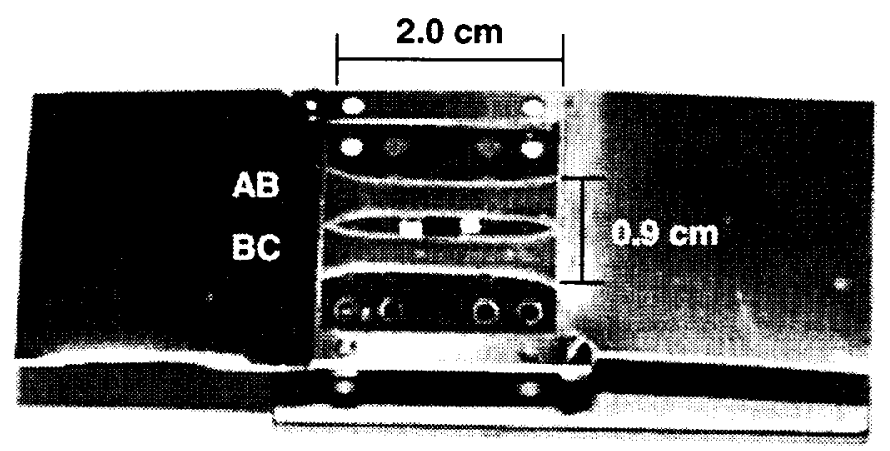

Fig. 2: Tensile samples mounted in the $x$-ray holder (without the Be filter).

3.2 Comparison of Air-Stored and Vacuum-Stored X-Ray Exposed Samples Table 3 lists the tensile properties for samples irradiated with the same $x$-ray exposure conditions and then stored in air or vacuum. Uncertainties represent the standard deviation of the samples tested. The samples stored under vacuum up to 115.5 hours were under high vacuum until tensile testing. Whereas, those stored for 212 and 361 hours were initially stored under high vacuum, then transferred to low vacuum. The results indicate, as shown in Figures 3 and 4, that the samples stored in air have larger decreases in tensile properties than the samples stored under vacuum. Samples stored under vacuum (for up to 400 hours) show no further decrease in tensile properties over time, while samples stored in air (for up to 900 hours) appear to show continued decreases in percent elongation to failure over time. More data points are needed to verify this trend. 
Table 3. Tensile Results for X-ray Exposed FEP Stored in Air and Under Vacuum.

\begin{tabular}{cccc}
\hline $\begin{array}{c}\text { Time in Storage } \\
\text { (hours) }\end{array}$ & $\begin{array}{c}\text { UTS } \\
\text { (MPa) }\end{array}$ & $\begin{array}{c}\text { Elongation at Failure } \\
\%\end{array}$ & $\begin{array}{c}\text { Samples } \\
\#\end{array}$ \\
\hline 1 & $13.2+/-0.8$ & $135.7+/-19.0$ & 6 \\
24 & $13.5+/-0.6$ & $166.4+/-17.4$ & 6 \\
48 & $12.8+/-0.3$ & $153.6+/-11.4$ & 5 \\
96 & $13.2+/-0.4$ & $142.2+/-17.7$ & 3 \\
192 & $12.5+/-0.5$ & $132.8+/-26.5$ & 4 \\
336 & $13+/-0.2$ & $112.3+/-33.1$ & 6 \\
907 & $13.1+/-0.2$ & $82.0+/-6.6$ & 4 \\
\hline \multicolumn{4}{c}{ Vacuum-Storage } \\
Time in Storage & UTS & Elongation at Failure & Samples \\
(hours) & $($ MPa) & $\%$ & $\#$ \\
\hline 15 & $14.7+/-0.5$ & $173.3+/-19.8$ \\
17.5 & $14.5+/-0.3$ & $181.6+/-7.8$ & 4 \\
25.5 & $14.3+/-0.6$ & $185.1+/-7.5$ & 2 \\
66 & $13.8+/-0.8$ & $152.0+/-23.5$ & 4 \\
88.5 & $14.7+/-0.5$ & $190.5+/-8.6$ & 2 \\
115.5 & $14.2+/-0.5$ & $192.0+/-6.1$ & 2 \\
212 & $14.5+/-0.5$ & $177.4+/-10.7$ & 4 \\
361 & $14.3+/-0.2$ & $179.7+/-5.4$ & 2 \\
\hline
\end{tabular}

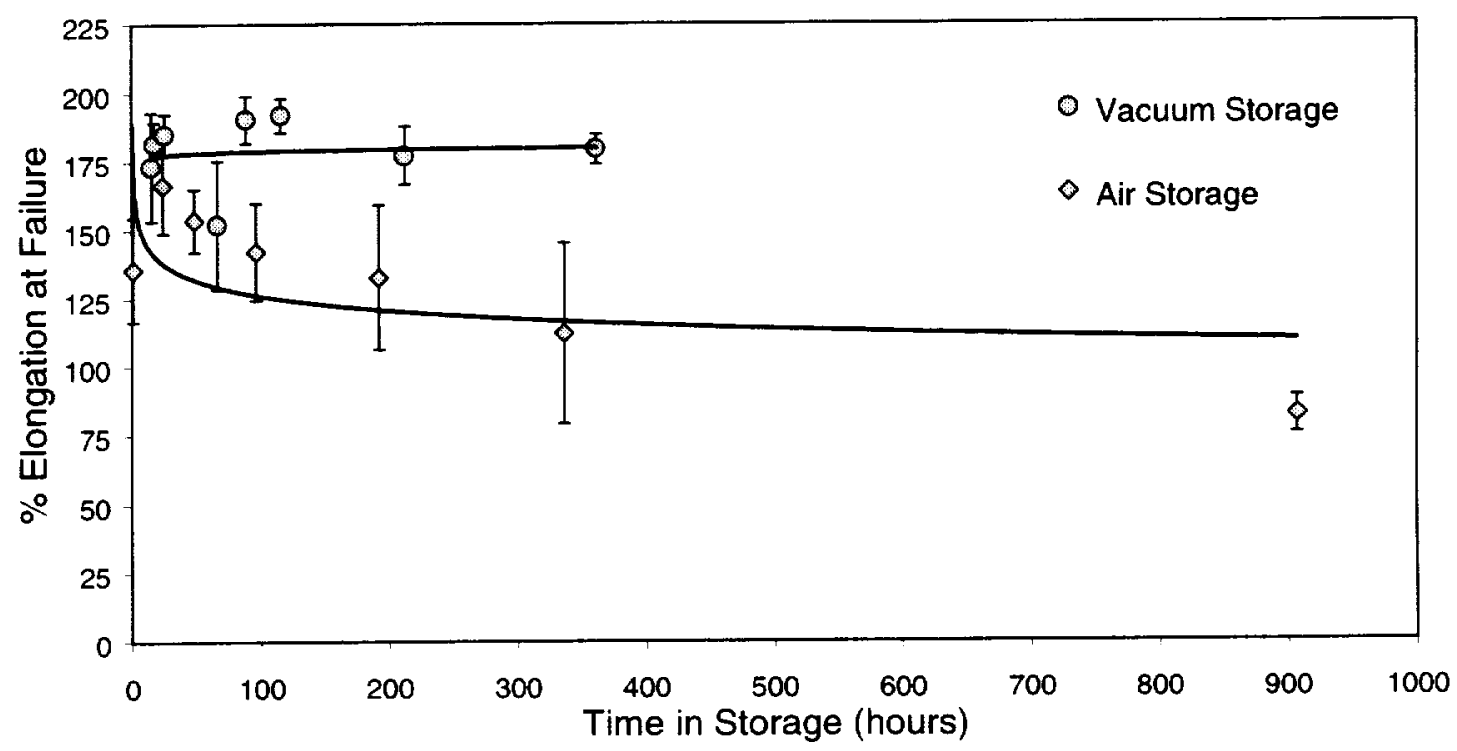

Fig. 3: Percent elongation at failure as a function of time stored in air or under vacuum. 


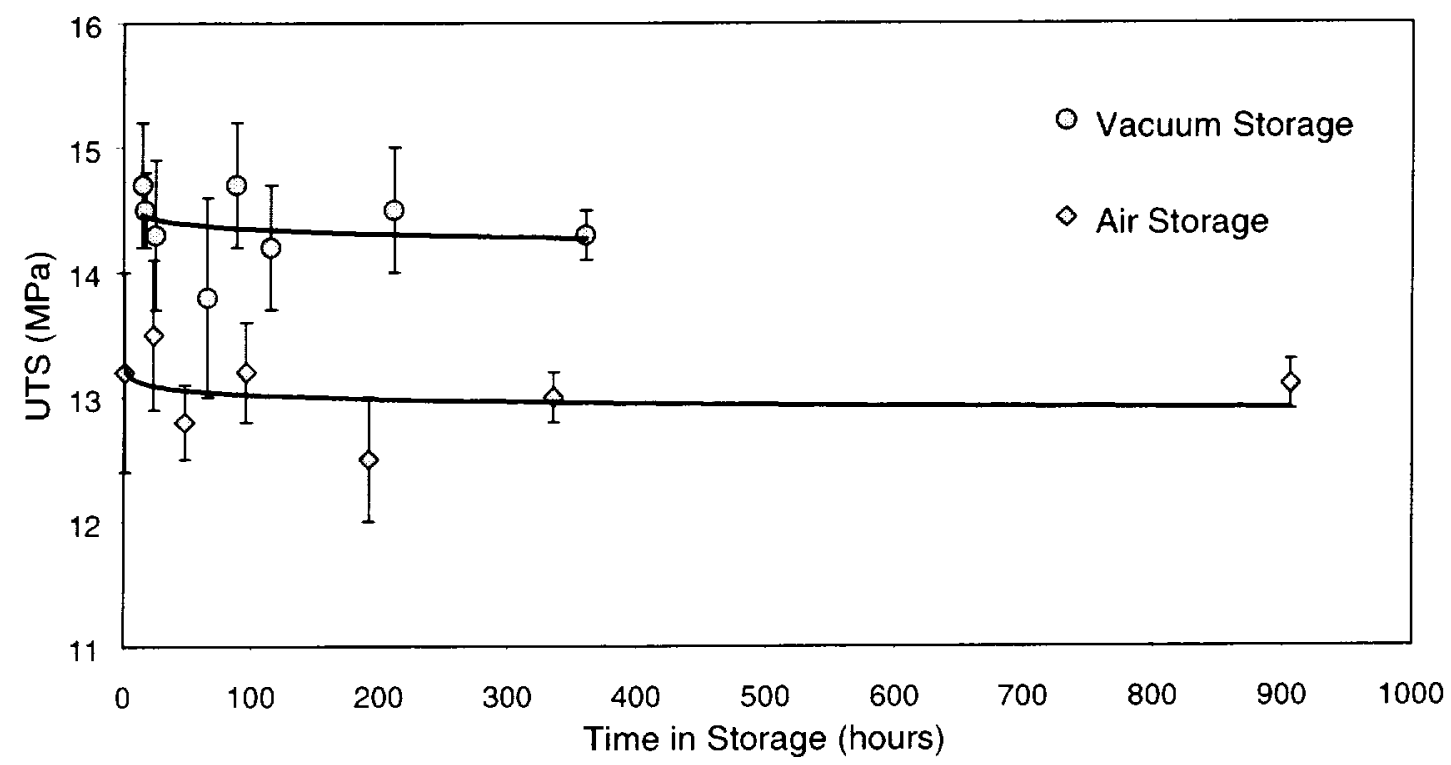

Fig 4: Ultimate tensile Strength (UTS) as a function of time stored in air or under vacuum.

The x-ray-exposed samples that were stored in air developed a hazy/white appearance in the irradiated area over time, as shown in Figure 5. This hazy appearance did not develop on the samples that were stored under vacuum.
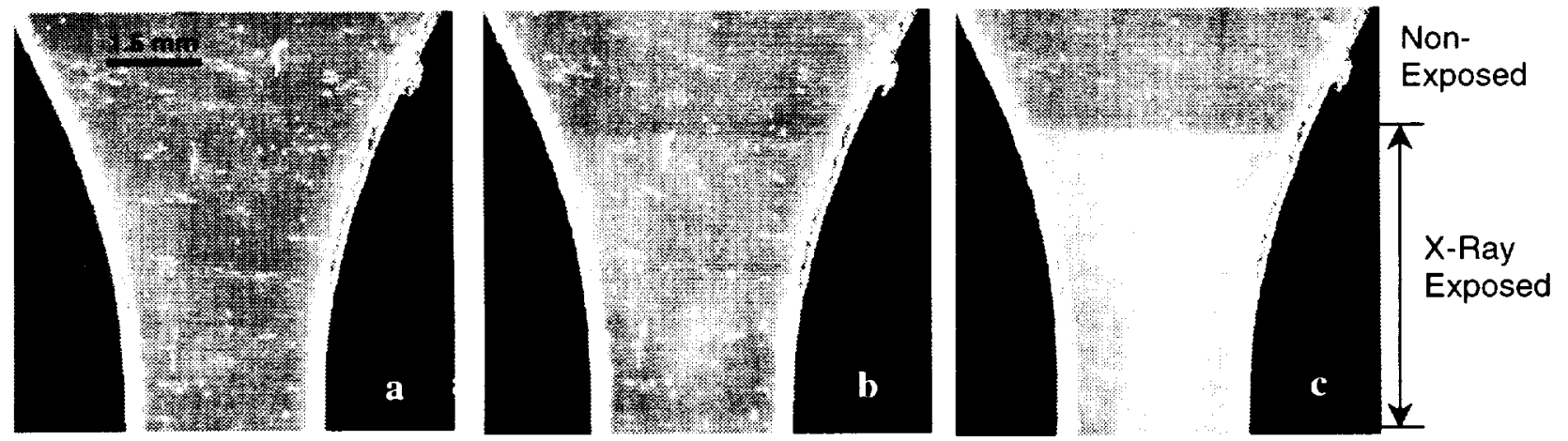

Fig 5: Development of hazy appearance in an x-ray exposed sample, after air-storage for: a). 25 minutes, b). 27 hours, and c). 118 hours.

Optical samples (2.54 $\mathrm{cm}$ square) were prepared and irradiated under the same $\mathrm{x}$-ray exposure conditions as the tensile samples so that changes in optical properties could be measured and corresponded to the hazy-white appearance. Table 4 lists solar reflectance, solar absorptance, and thermal emittance data for an optical sample. The changes in optical properties over time for this $\mathrm{x}$-ray exposed and air-stored sample can be seen in Figure 6. The hazy appearance primarily increases the diffuse reflectance, but small solar absorptance increases occur also. 
The source of the haziness was evaluated using scanning electron microscopy and atomic force microscopy. An irradiated tensile sample was cut in half and mounted on a SEM sample holder with both FEP and Al sides up for SEM analysis (instead of tensile testing). Unexposed and exposed areas were imaged at $0^{\circ}$ and $45^{\circ}$ tilt angles and compared. As can be seen in Figure 7 , the unexposed FEP and $\mathrm{Al}$ surfaces look very similar with a slight texture observed at $2,500 \mathrm{X}$ magnification. The $\mathrm{X}$-ray exposed FEP surface looked similar to the unexposed surfaces, but the exposed Al surface appeared rougher with the apparent development of very small surface particles.

Table 4. Optical Properties of X-Ray Exposed Sample FEPOP3 after Various Air-Storage Times.

\begin{tabular}{cccccc}
\hline $\begin{array}{c}\text { Air-Storage } \\
\text { Time } \\
\text { (Hours) }\end{array}$ & $\begin{array}{c}\text { Total } \\
\text { Reflectance } \\
\left(\rho_{\mathrm{t}}\right)\end{array}$ & $\begin{array}{c}\text { Diffuse } \\
\text { Reflectance } \\
\left(\rho_{\mathrm{d}}\right)\end{array}$ & $\begin{array}{c}\text { Specular } \\
\text { Reflectance } \\
\left(\rho_{\mathrm{s}}\right)\end{array}$ & $\begin{array}{c}\text { Solar } \\
\text { Absorptance } \\
\left(\alpha_{\mathrm{s}}\right)\end{array}$ & $\begin{array}{c}\text { Thermal } \\
\text { Emittance } \\
\left(\varepsilon_{\mathrm{RT}}\right)\end{array}$ \\
\hline No Exposure & 0.875 & 0.082 & 0.793 & 0.125 & 0.787 \\
1 & 0.87 & 0.112 & 0.758 & 0.13 & 0.787 \\
25 & 0.861 & 0.138 & 0.723 & 0.139 & 0.787 \\
121 & 0.852 & 0.213 & 0.639 & 0.148 & 0.787 \\
308.5 & 0.85 & 0.232 & 0.618 & 0.15 & 0.786 \\
\hline
\end{tabular}

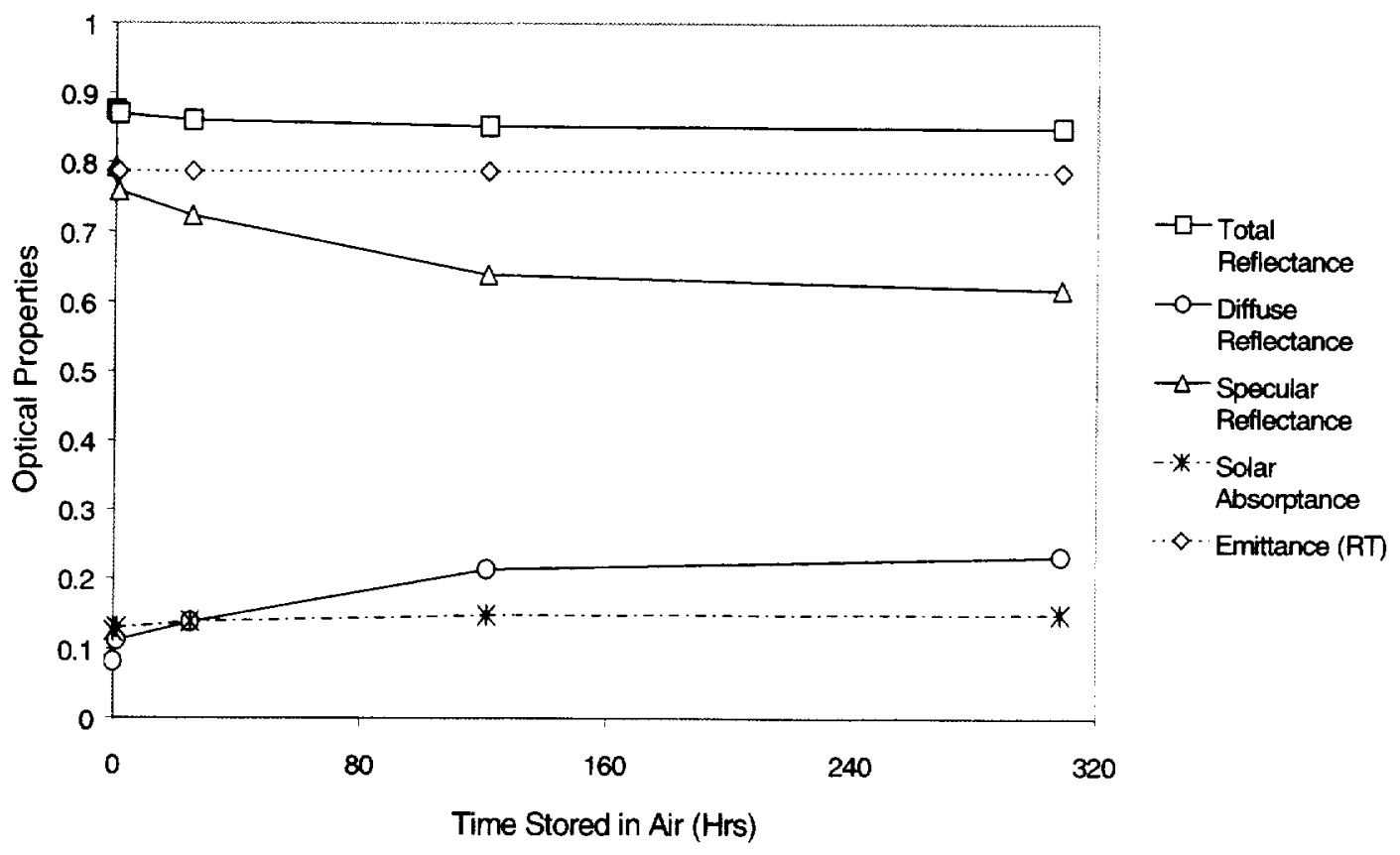

Fig. 6: Optical properties of irradiated sample FEPOP3 after various air-storage durations. 
Unexposed
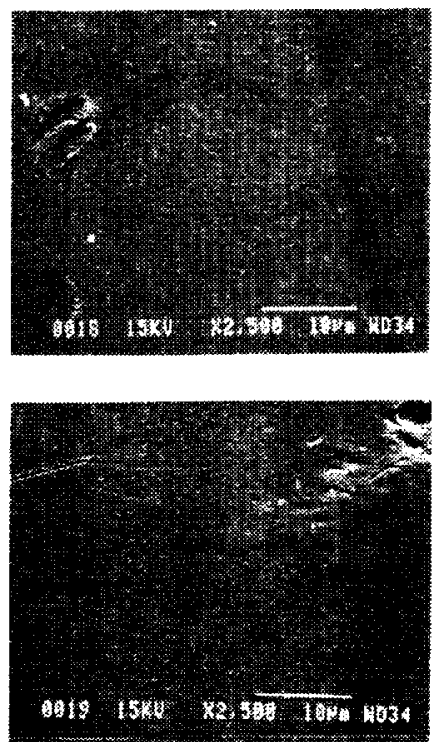

Exposed

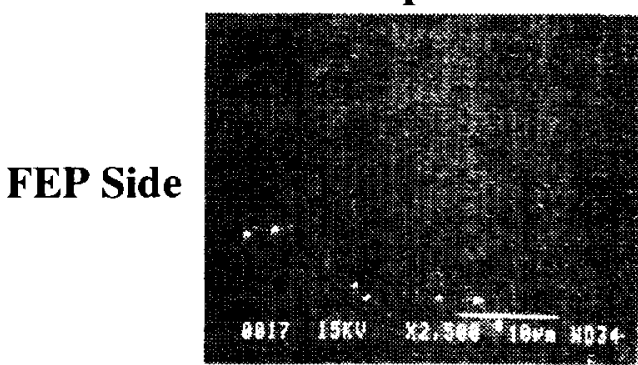

Al Side

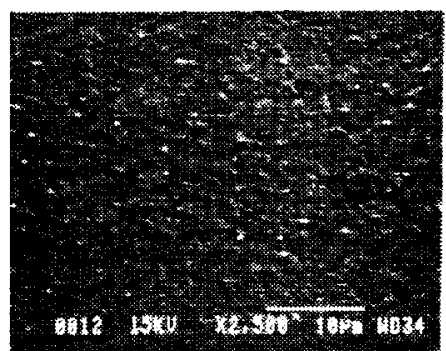

Fig. 7: SEM micrographs of unexposed and exposed areas of the FEP and Al sides of a x-ray exposed tensile sample at a $45^{\circ}$ tilt angle.

The AFM average RMS surface roughness values for various size scan areas of a x-ray exposed, airstored sample are listed in Table 5. The RMS roughness for the unexposed surfaces, and the exposed FEP surface are all very similar, while the exposed $\mathrm{Al}$ surface is more than 3 times as rough. This can be seen in the bar chart in Figure 8, where the RMS roughness for the $10 \times 10$ and $25 \times 25 \mu \mathrm{m}$ scan areas for the four different surfaces are compared. Figure 9 shows AFM 3-D topography images of the unexposed and $\mathrm{x}$-ray exposed Al surface.

Table 5. Surface Roughness for Exposed and Non-Exposed Regions of Irradiated Al-FEP.

\begin{tabular}{ccccc}
\hline $\begin{array}{c}\text { Scan Area } \\
(\mu \mathrm{m} \times \mu \mathrm{m})\end{array}$ & $\begin{array}{c}\text { FEP } \\
\text { Unexposed }\end{array}$ & $\begin{array}{c}\text { FEP } \\
\text { Exposed }\end{array}$ & $\begin{array}{c}\mathrm{Al} \\
\text { Unexposed }\end{array}$ & $\begin{array}{c}\mathrm{Al} \\
\text { Exposed }\end{array}$ \\
\hline $5 \times 5$ & 77.3 & 59.1 & - & - \\
$10 \times 10$ & 82.7 & 76.5 & 97 & 361 \\
$25 \times 25$ & 92.2 & 87.2 & 95 & 335 \\
$50 \times 50$ & 102 & 118 & 107 & - \\
$72 \times 72$ & - & - & 103 & 362 \\
\hline
\end{tabular}




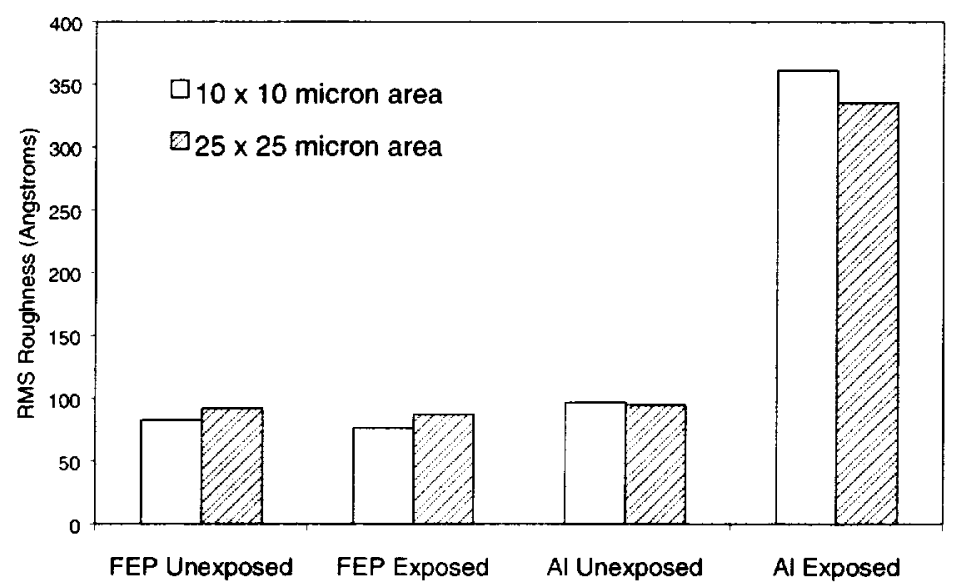

Fig. 8: RMS Roughness for $10 \times 10$ and $25 \times 25$ micron square scan areas for unexposed and irradiated areas of both $\mathrm{Al}$ and FEP surfaces.
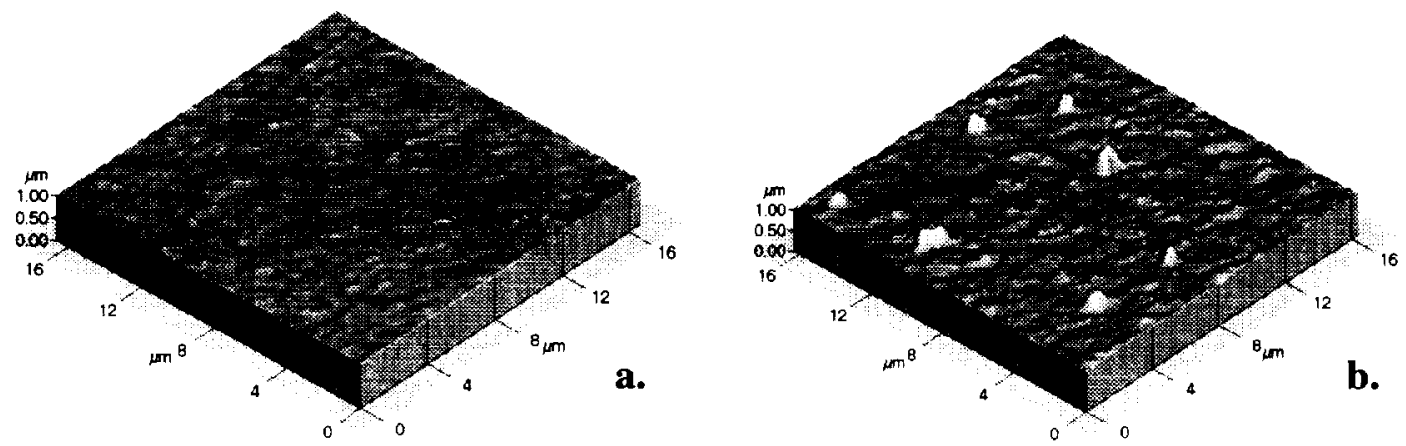

Fig. 9: AFM 3-D topography images of the Al surface of an irradiated sample: a). unexposed area, and b). $x$-ray exposed area.

The haziness was found to correspond to a roughening of the aluminized-side of the sample. The exact nature of the surface roughening, and the development of small bumps on the aluminized surface of the irradiated Al-FEP is not known. A tape peel test was conducted on irradiated and non-irradiated regions of the sample used for SEM examination. Irradiation was speculated to produce outgas molecules and contribute to the surface roughening and possibly weakening of the FEP-Al interface adhesion force. The aluminum was found to peel away from the FEP in the irradiated region, and not in the nonirradiated region. This distinction can be seen in Figure 10. It would be of interest to conduct $x$-ray photoelectron spectroscopy (XPS) analyses to get a better understanding of the chemical changes at these surfaces. 


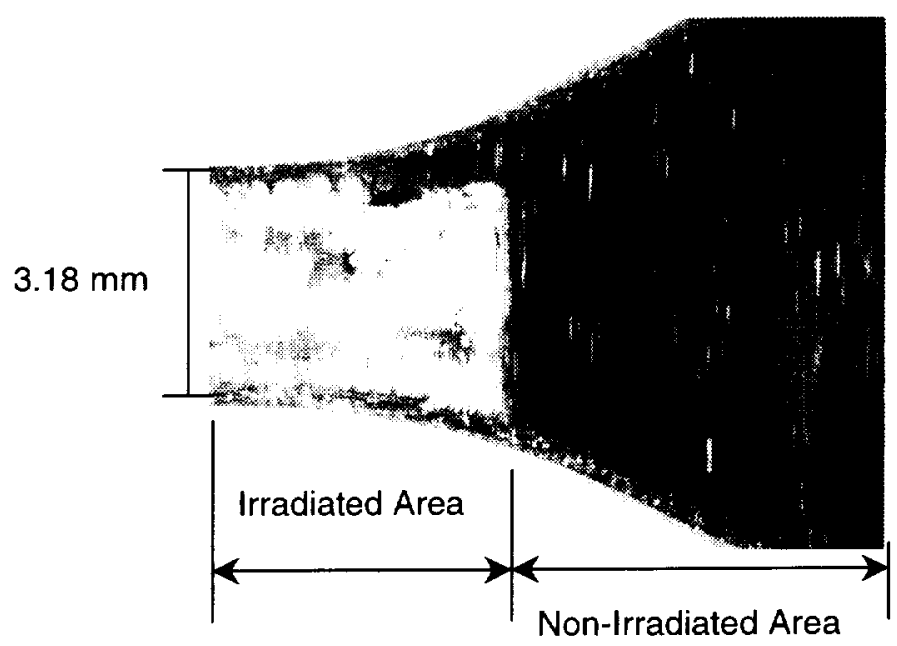

Fig. 10: Irradiated and air-stored sample after tape peel testing. A distinct difference in the adhesion of the $\mathrm{Al}$ to FEP is observed between the irradiated and non-irradiated areas.

It is not known if atomic oxygen in the space environment plays a similar role in contributing to increased degradation of tensile properties of irradiated FEP such as molecular oxygen does in these ground-tests. The competing roles of erosion versus contribution to embrittlement from atomic oxygen would be of interest to study. Variations in atomic oxygen fluence versus irradiation exposure (for equivalent sun hours exposure) have been shown to have an effect on FEP embrittlement in the space environment. ${ }^{5}$ Controlled synergistic atomic oxygen and x-ray exposure tests of FEP would be interesting to conduct with respect to tensile properties.

\section{4-SUMMARY \& CONCLUSIONS}

Based on a limited number of test data from space-exposed FEP, which showed a trend for continued degradation over time, an investigation was conducted to evaluate the effect of air and vacuum storage on the mechanical properties of $x$-ray exposed FEP. Aluminized-FEP (127 $\mu \mathrm{m}$ thick) tensile samples were $\mathrm{x}$-ray exposed with $15.3 \mathrm{kV} \mathrm{Cu} \mathrm{X}$-rays for 2 hours. X-ray exposed samples were stored in air or under vacuum for various time periods prior to tensile testing. Tensile results indicate that the samples stored in air have larger decreases in tensile properties than for the samples stored under vacuum. Samples stored under vacuum (for up to 400 hours) show no further decrease in tensile properties over time, while samples stored in air (for up to 900 hours) appear to show a trend for continued decrease in percent elongation to failure over time. Irradiated samples stored in air developed a hazy appearance in the $\mathrm{x}$-ray-exposed area. The source of the haziness was evaluated using scanning electron microscopy and atomic force microscopy. The haziness was found to reside at the Al/FEP interface as witnessed by increased surface roughness of the aluminized side of the material, and dramatic decrease in the adhesion between the Al and FEP. Optical properties of air-stored irradiated samples show an increase in the diffuse reflectance, which is consistent with the observed roughening, characterized by AFM. These findings indicate that air exposure plays a role in the degradation of $x$-ray irradiated FEP. These results indicate that proper sample handling and storage is necessary with space retrieved materials.

Future studies will include testing of x-ray exposed samples stored in air and under vacuum for longer durations than reported here, and increasing the number of data points at storage times reported. It appears that the majority of degradation due to air-exposure occurs relatively quickly, so a more careful 
analysis of degradation of air-stored samples, stored up to 50 hours, is planned. Also, based on these results Al-FEP material recently retrieved from the HST is being analyzed over time. Tensile samples have been prepared and are being stored under vacuum, and in air, and will be tested over a period of a year. Lastly, it is not known if atomic oxygen in the space environment plays a similar role in contributing to increased degradation of tensile properties of irradiated FEP, but the competing roles of erosion versus increased degradation would be of interest to study in controlled experiments.

\section{5 - ACKNOWLEDGMENTS}

The authors would like to thank Dr. Donald Wheeler and Dr. Stephen Pepper of the NASA Glenn Research Center for the use of their $x$-ray facility, and for quantitative characterization of the $x$-ray source and energy deposition within the FEP samples. The authors are also very appreciative to Douglas Wright of Cleveland State University for computing the percent elongation to failure for the test data, and Russell Messer, also of Cleveland State University for writing the program for elongation computation.

\section{6 - REFERENCES}

1. J. H. Henninger, NASA RP 1121, April 1984. (thermal control properties)

2. http://setas-www.larc.nasa.gov/LDEF/index.html

3. http://setas-www.larc.nasa.gov/LDEF/TECH_DISC/mat.html

4. A. E. Stiegman, D. E. Brinza, E. G. Laue, M. S. Anderson and R. H. Liang, Journal of Spacecraft and Rockets, Vol. 29, No. 1, Jan-Feb. 1992, pp. 150-151.

5. K. K. de Groh, and D. C. Smith, NASA TM 113153, 1997.

6. H. G. Pippen, NASA CR 4663, July 1995.

7. T. M. Zuby, K. K. de Groh, and D. C. Smith, Proceedings of the Hubble Space Telescope SolarArray Workshop, ESA WPP-77, 385 (1995); also NASA TM 104627, Dec. 1995.

8. P. A. Hansen, J. A. Townsend, Y. Yoshikawa, D. J. Castro, J. J. Triolo, and W. C. Peters, SAMPE International Symposium, $\underline{43}, 570$, (1998).

9. J. A. Townsend, P. A. Hansen, J. A. Dever, K. K. de Groh, B. A. Banks, L. Wang and C. He, 1999 High. Perform. Polym. 11, 81-99 (1999).

10. B. A. Banks, K. K. de Groh, T. J. Stueber, E. A. Sechkar, and R. L. Hall, SAMPE International

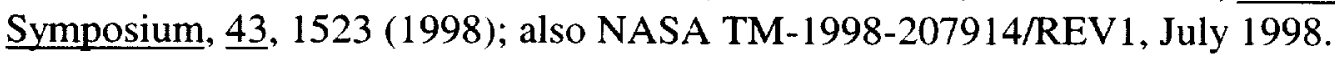

11. R. L. Hall and B. A. Banks, personal communication.

12. S. V. Pepper and D. R. Wheeler, Review of Scientific Instruments, Vol.71, No. 3, March 2000, 1509-1515.

13. S. V. Pepper, D. R. Wheeler and K. K. de Groh, "Quantitative Study of Degradation of PTFE and FEP Films by Soft X-Rays," to be published in the proceedings for the $8^{\text {th }}$ ISMSE $\& 5^{\text {th }}$ ICPMSE conference, June 5-9, 2000, Arcachon, France.

14. S. V. Pepper, personal communication.

15. D. A. Gulino, NASA TM 88914, January 1987. 



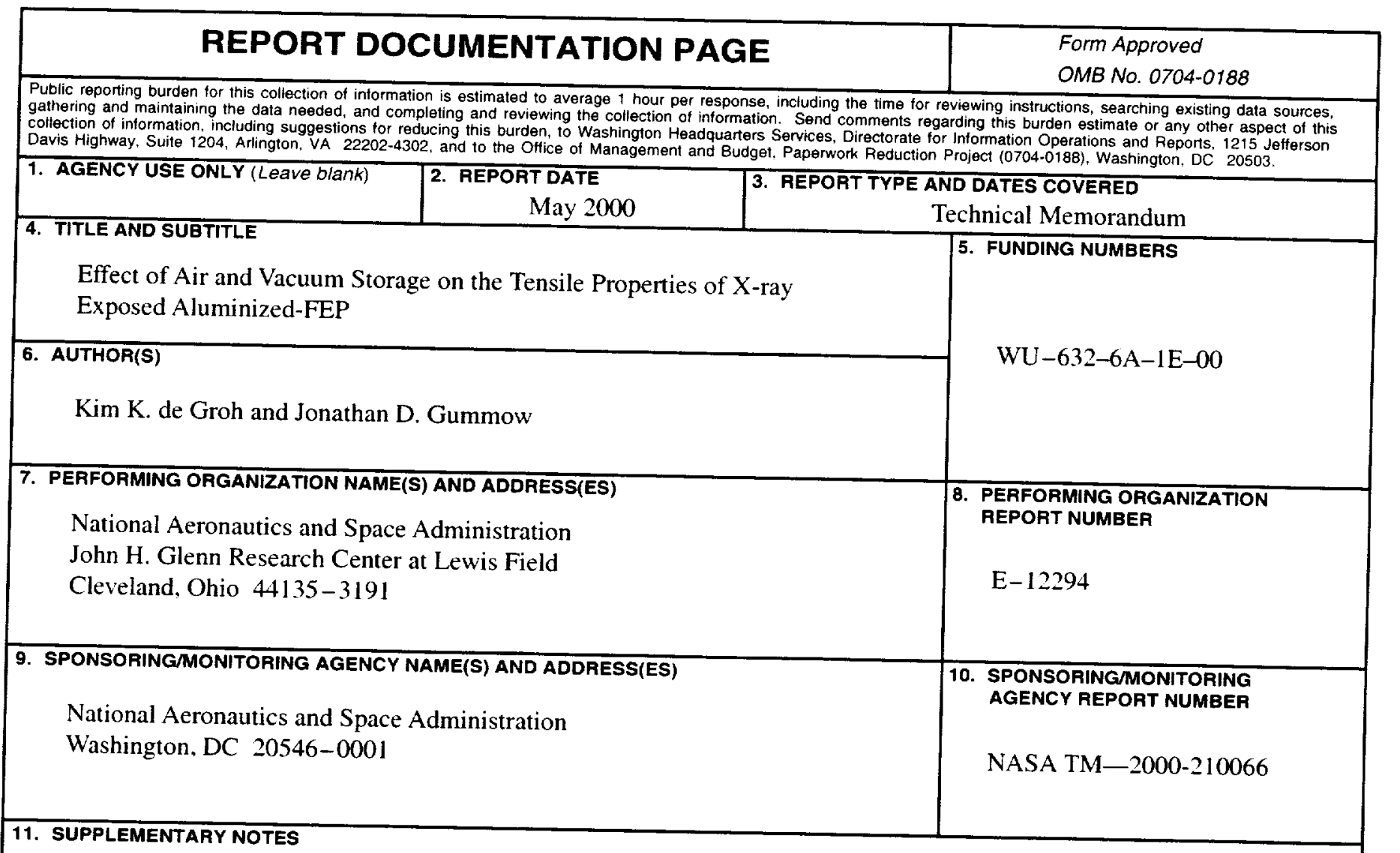

Prepared for the 8th International Symposium on Materials in a Space Environment and the 5th International Conference on Protection of Materials and Structures for the LEO Space Environment cosponsored by the CNES, ONERA. ESA, ITL, Inc., and
the CSA, Arachon. France. June 5-9, 2000. Kim K. de Gro the CSA. Arachon, France, June 5-9, 2000. Kim K. de Groh. NASA Glenn Research Center; and Jonathan D. Gummow, Ohio 5480, (216) 433-2297.

\begin{tabular}{|l|l|l} 
12a. DISTRIBUTION/AVAILABILITY STATEMENT & 12b. DISTRIBUTION CODE
\end{tabular}

Unclassified - Unlimited

Subject Categories: 18, 27, and 92

Distribution: Nonstandard

This publication is available from the NASA Center for AeroSpace Information. (301) 621-0390.

\section{ABSTRACT (Maximum 200 words)}

Metallized Teflon ${ }^{\circledR}$ FEP (fluorinated ethylene propylene), a common spacecraft thermal control material, from the exterior layer of the Hubble Space Telescope (HST) has become embrittled and suffers from extensive cracking. Teflon samples retrieved during Hubble servicing missions and from the Long Duration Exposure Facility (LDEF) indicate that there may be continued degradation in tensile properties over time. An investigation has been conducted to evaluate the effect of air and vacuum storage on the mechanical properties of $x$-ray exposed FEP. Aluminized-FEP (Al-FEP) tensile samples were irradiated with $15.3 \mathrm{kV} \mathrm{Cu} x$-rays and stored in air or under vacuum for various time periods. Tensile data indicate that samples stored in air display larger decreases in tensile properties than for samples stored under vacuum. Air-stored samples developed a hazy appearance, which corresponded to a roughening of the aluminized surface. Optical property changes were also characterized. These findings indicate that air exposure plays a role in the degradation of irradiated FEP, therefore proper sample handling and storage is necessary with materials retrieved from space.

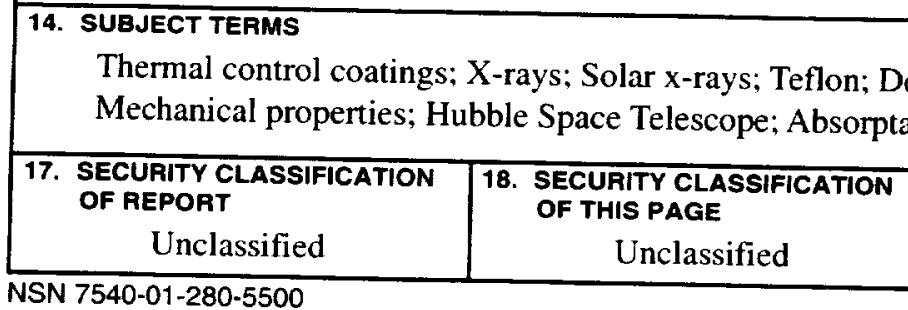

15. NUMBER OF PAGES 18

16. PRICE CODE

$\mathrm{AO} 3$

20. LIMITATION OF ABSTRACT

9. SECURITY CLASSIFICATION OF ABSTRACT Unclassified 